\title{
O PROFESSOR-ARTISTA: PERSPECTIVAS TEÓRICAS E DESLOCAMENTOS HISTÓRICOS
}

\author{
Biange Cabral
}

O ensino do teatro, na escola e na comunidade, reflete as formas teatrais contemporâneas ao mesmo tempo em que responde aos avanços das teorias da educação.

A partir dos anos 60, o teatro experimental enfatiza as noções de presença e a interação ator-espectador, e estas constituem a base para pensar o teatro como processo em sala de aula. Nos últimos dez anos, outras influências das práticas teatrais contemporâneas estão presentes na pedagogia do teatro fragmentação, abordagem não linear e descontínua ao argumento, releitura e apropriação dos temas e textos clássicos, constante mudança de perspectivas.

Para Grotowski, o valor particular dos clássicos está no fato de que eles já existem como arquétipos na mente do público e carregam uma ressonância generalizada que está muito próxima do mito. "A força das grandes obras realmente consiste em seu efeito catalisador: elas abrem portas para nós (...) para ambos, produtor e ator, o texto é um tipo de bisturi possibilitando-nos abrir a nós mesmos, transcender a nós mesmos, achar o que está escondido dentro de nós" (1987:49). A extensão e o caráter da releitura de um texto clássico são determinados pela lógica interna do processo de investigação e pelo contex to e circunstâncias em que foi gerado o projeto de montagem - com freqüência o texto original torna-se irreconhecível, mesmo quando mantidos os padrões de relacionamentos e tensões.

Cecily O’Neill considera que o professor, ao retomar um texto clássico, o utiliza como 'material esperando significação', como objeto de um jogo. “O líder ou professor, inserido no processo criativo, pode assumir algumas 
das funções de um diretor, produtor, encenador, ou mesmo espectador; mas, dada a função da atividade, irá além destes propósitos. As tarefas básicas do líder são aquelas de administrar a ação, operar a estrutura, e funcionar como dramaturgista” (O’Neill, 1995:64).

A releitura e apropriação dos temas e textos clássicos pode ser uma forma de responder à dificuldade, usualmente apontada por professores, quer para encontrar um texto que dê espaço e voz para uma turma de 30 alunos, quer para estruturar e coordenar um processo de criação coletiva. $\mathrm{O}$ tex to como objeto de um jogo, como afirma O’Neill acima, oferece ao professor não apenas um ponto de partida, mas também uma delimitação para suas ações pedagógicas: conceitos e situações a serem investigados cenicamente, fragmentos de texto a serem improvisados, aproximação com o contex to atual dos participantes através de seu cruzamento com memórias, histórias locais, e mesmo outros textos.

Esta re-significação do texto direciona a atenção para a sua função cognitiva. Que conhecimentos o aluno adquire ao interagir com o tex to e a cena? Aqui cabe considerar as diferenças e especificidades dos tipos de conhecimento adquiridos com o fazer teatral, considerando-se que estes por sua vez diferem se o aluno participar como ator ou espectador. Focalizar a ação pedagógica requer pensar a função cognitiva e esta está diretamente associada ao maior ou menor grau de intervenção do professor no processo de criação, o que também se associa ao caráter do texto usado, e consequentemente gerado.

\section{Retrospectiva Histórica}

A forma usual pela qual esta intervenção do professor tem sido pensada, no Brasil, tem sido através da comparação entre o jogo teatral e o jogo dramático. A primeira distinção neste sentido, a ser amplamente difundida, foi realizada por Sandra Chacra:

“ojogoteatralfaznascerum 'texto' pormeio do desenvolvimento
de uma linguagem teatral consciente, objetiva e comunicável, no
instante da representação. Do mesmo modo que encontramos um
caráter improvisacional na obra formalizada do teatro, encontramos
um caráter formalizado no jogo improvisado. É esse aspecto que lhe
confere caráter "textual" no sentido de 'comunicação' e não somente de
'auto-expressão'”. (CHACRA, 1983:66-67)

A autora analisa esta perspectiva a partir do método de improvisação teatral de Viola Spolin (1979). Uma visão oposta com, respeito 


\section{Urdimento}

à função do texto no processo de exploração teatral com crianças, diz ela, é a do inglês Peter Slade (1971) ${ }^{1}$ :

"Negando não somente a peça literária, mas também qualquer intenção planejada de trabalho para uma audiência, o 'jogo dramático infantil' é por ele considerado como 'uma forma de arte por direito próprio', sendo que "nem na experiência pessoal nem na experiência do grupo existe qualquer consideração de teatro no sentido adulto, a não ser que 'nós a imponhamos (...) Ao brincarem espontaneamente, as crianças 'representam' as suas vivências pessoais, o seu mundo real ou imaginário, estimuladas e encorajadas pelo adulto (professor ou qualquer outra pessoa), através de um processo de 'nutrição' do jogo, que não é o mesmo que interferência, fazendo expandir um texto, cujo sentido é mais o de 'expressão' (auto-expressão), do que o de 'comunicação'”. (CHACRA, 1983:68)

Retomar esta distinção, após vinte anos, justifica-se devido à atualidade da contraposição jogo dramático - jogo teatral nas publicações no campo da pedagogia do teatro, e da associação do primeiro com a influência de Peter Slade e uma tradição inglesa no campo do teatro na escola. An Introduction to Child Drama, o livro mais difundido de Slade, foi traduzido para o português por Tatiana Belinky, como O Jogo Dramático Infantil (Summus Editorial, 1978). Entretanto, na perspectiva de Slade à época desta publicação, 'child drama' se referia ao brincar ou ao 'fazer de conta' da criança; assim como 'play way', expressão usada por seus contemporâneos, se referia à maneira/forma de brincar ('play' pode ser traduzido tanto como jogar ou brincar)². Pela sua ótica, o "Child Drama" não inclui regras de nenhum tipo, nem mediação do professor ao nível do desenvolvimento da atividade, não apresentando característica de jogo, a não ser que o traduzíssemos por 'jogo simbólico’. Brian Way, discípulo de Slade, afirma em Development through Drama (Desenvolvimento através do Drama): "nós estamos preocupados com o desenvolvimento de pessoas, não do drama (e certamente não do teatro)” (1967).

A associação do Child Drama com o jogo dramático, no contexto brasileiro, em contraposição ao jogo teatral, com freqüência conduz a uma prática com características que a aproxima do jogo simbólico. A este respeito, acentua Maria Lúcia Pupo,

(...) ter simplesmente a sistematização e enriquecimento do jogo simbólico como perspectiva de trabalho em Teatro-Educação equivale a não

${ }^{1}$ As datas de publicação das obras de Spolin e Slade se referem às datas de publicação das traduções brasileiras. A primeira tradução de Spolin, por Eduardo Amos e Ingrid Koudela, se refere à tese de doutorado de Spolin, publicada em 1963. 0 primeiro texto publicado por Slade, Child Drama, se deu em 1954, e An Introduction to Child Drama em 1958.

2É desta época 0 costume de construir atrás da escola uma casinha de bonecas, completamente equipada, onde as crianças possam brincar. 


\section{Urdimento}

${ }^{3}$ Também conhecido como process drama, drama as a teaching method, ou a learning method (dependendo da perspectiva pela qual é investigado ou analisado).

${ }^{4}$ Professor-personagem foi minha tradução para teacher-inrole, e assim como a tradução de Belinky para child drama, decorreu em parte devido à dificuldade de encontrar um termo adequado para "professor-nopapel" (social). Porém dentro do conceito de teacher-in-role estão inseridas as dimensões de representação e presença; Heathcote, por exemplo, interpreta e mantém personagens de outras épocas, lugares, textos, para contrapô-los às atitudes dos alunos, e no mesmo processo de drama, assume papéis sociais que facilitem sua mediação no jogo.

${ }^{5}$ Participei dos dramas "Mary Morgan", "The Good Samaritan", "Dr. Knox", "The Romans", "Chanel Islands", "Living in a Dictatorship", "The Oxfam Project". Os registros destes processos são encontrados no Dorothy Heathcote Archive, mantido pela Manchester Metropolitan University/UK. considerar que este brinquedo já cumpriu sua função em termos da articulação básica entre a realidade objetiva e a subjetiva. (PUPO, 1986:12)

No entanto, o jogo dramático, enquanto atividade que inclui aquisição de conhecimentos no campo específico do teatro, associa-se à tradição do jeu dramatique, da tradição francesa. Neste sentido a contribuição de Maria Lucia Pupo (acima) e a recente publicação de Flávio Desgranges (2006), são fundamentais para o entendimento da distinção entre o Child Drama (o play way de Slade) e o jogo dramático (da tradição francesa). Desgranges sintetiza a caracterização e funções do jeu dramatique:

\section{(...) uma atividade grupal, em que o indivíduo elabora por si e} com os outros as criações cênicas, valendo-se das apresentações no interior das oficinas como um meio de investigação e apreensão da linguagem teatral. Desenvolvem-se, no decorrer do processo, as possibilidades expressiva e analítica, exercitando o participante tanto para dizer algo através do teatro, quanto para uma interpretação aguda dos diversos signos visuais e sonoros que constituem uma encenação teatral; estimulando-o, ainda, a tornar-se um observador atento em sua relação com as diversas produções espetaculares. (DESGRANGES, 2006:95)

Quanto à associação de Slade com a tradição inglesa, cabe aqui ressaltar sua distinção de outra tradição inglesa, o Drama in Education ${ }^{3}$, criado por Dorothy Heathcote, a partir da segunda metade dos anos 50. Heathcote priorizava (ainda prioriza) a ampliação do conhecimento do aluno através de uma preocupação com a forma: confrontos espaciais, signos visuais de linguagem (cartões, posters, banners, rótulos, manchetes), atuação dialética através de uma troca de enquadramentos e papéis, foco no gesto. A quantidade e a qualidade das informações sobre o contexto e a situação a serem investigados permitem associar sua atuação a uma abordagem enciclopédica, caracterizada por uma intervenção ao nível da estrutura, da ênfase na forma, do questionamento pelo professor, como personagem. Entretanto, o texto resultante é de autoria do aluno; o material introduzido - imagens, textos, discurso do professorpersonagem ${ }^{4}$ - é desconstruído e torna-se uma pista para mediar interações.

Esta característica enciclopédica do drama é associada aos diversos graus de intervenção do professor. Ao participar de processos de drama conduzidos por Heathcote, entre 1990 e 1994 (Birmingham/UK), meu maior impacto foi com a intensidade e densidade dos textos e imagens que subsidiaram os processos ${ }^{5}$. Textos e imagens foram coletados de romances históricos ou documentários jornalísticos, sobre situações-limite 
de sofrimento e opressão, que eram aproximadas e distanciadas através de um método, cuja poética inclui acesso a informações, linguagem, história, cultura e política, além de conhecimentos da linguagem cênica. A postura do professor é a daquele que desafia os pressupostos do texto ou pré-texto e aqueles introduzidos no decorrer do processo, pelo grupo, investigando através do drama as motivações ocultas que determinaram as ações e atitudes de opressão. O impacto nos participantes está relacionado com a ampliação de seu capital cultural e lingüístico, associado ao engajamento emocional com o material introduzido.

\section{Entre a teoria e a pedagogia}

Quer se fale de jogo dramático, do jogo teatral, ou do drama, não há como deixar de reconhecer o papel central das interações do fazer teatral com outras áreas de conhecimento. Processos de montagem, criação coletiva, investigações cênicas, interagem com temáticas, idéias, imagens. Seu diretor/ professor media as interações entre os participantes, e destes com o espaço, o tempo, a cena, o contexto da ficção.

É a partir desta constatação que se deve pensar no papel do professor. O cruzamento de áreas e subáreas do conhecimento, no fazer teatral, aponta para a interdisciplinaridade. A heterogeneidade do grupo indica uma abordagem intercultural. Entretanto, o professor de teatro, por um lado é pressionado a decorar e animar as datas comemorativas, por outro lado, vê seu espaço de atuação ser considerado descartável - um espaço para ser substituído por qualquer atividade emergente ou compromisso de última hora da administração escolar. A complexidade deste quadro, que persiste nos dias atuais, requer uma reflexão sobre a postura, atitudes e ações do professor no campo da escola.

$\mathrm{O}$ ensino do teatro no contexto curricular requer sejam repensadas as relações entre o teatro e a escola a partir das interações possíveis entre metodologias e espaço real, não apenas o necessário. Observações de estagiários e depoimentos de professores revelam que estes se voltam para as áreas de desenho, história da arte, confecção de fantoches (sem espaço para a construção da narrativa e manipulação), dobraduras. O ensino do teatro (e a escola em geral) padece com a falta de investimento em formação continuada e atualização do professor. Com sobrecarga de turmas e uma disciplina que envolve movimento, som, reformulação do espaço disponível e trabalho em grupos, o professor de teatro acaba reproduzindo uma relação ensino-aprendizagem que vai gradualmente estabelecendo uma rotina e se afastando da reflexão teórica e prática. 
Pierre Bourdieu (2007, 2004, 2001), usa o conceito de habitus para se referir à reprodução social e à resistência a mudanças. Para ele, o habitus está localizado na tradição e no estilo de vida, é internalizado na mente e inscrito no corpo e suas formas de expressão. As experiências reiteradas na infância, enfatizadas pelos discursos e regras de comportamento das instituições família, escola e mídia, delimitam e enquadram a forma pela qual o indivíduo age e responde a novas experiências e informações.

O habitus funciona assim como um mecanismo de controle que filtra as impressões e expressões do sujeito no presente. Neste sentido, é sua história incorporada e internalizada - esquecida como história; presença ativa do passado que se manifesta nos pensamentos e ações do presente. Enquanto defesa contra mudanças, ele não só rejeita novas informações como evita a exposição a tais informações. Desta forma explica como o indivíduo prefere discutir e conviver com aqueles com quem compartilha a mesma opinião. Também explica como discursos e opções sistemáticas são mantidos e como a crítica é rejeitada.

Como professora da disciplina Teatro na Escola - Estágio I (CEART/ UDESC), que inclui 20 horas-aula de observação em escolas e posterior seminários para a discussão dos problemas, possibilidades e potencial das metodologias focalizadas durante o restante do semestre, reuni uma série de exemplos que considero possam apontar para o habitus no contexto do ensino do teatro: aquecimento sem relação com a aula propriamente dita, improvisação sem contextualização, atividades que não introduzem conhecimentos específicos em teatro (dinâmicas de grupo que tendem a se constituir como a aula em si), tarefas ou trabalhos em grupos sem input do professor, falta de concepção cênica que direcione o processo, aulas baseadas em 'uma novidade para cada encontro' - o jogo do dia, baixas expectativas quanto ao trabalho a ser desenvolvido, barateamento dos resultados - aceitação dos produtos apresentados, sejam eles quais forem.

Como responder a este quadro? Que teorias poderiam subsidiar a formação do professor?

A complexidade dos saberes e fazeres contemporâneos aponta para o papel do professor como intelectual, que na concepção de Henri Giroux é entendido como

"aquele que desperta a memória, o reconhecimento de exemplos de sofrimentos passados, públicos e privados, os quais exigem 
compreensão (...) aquele de desvenda a dignidade e a solidariedade da resistência, que chama nossa atenção para as condições históricas que construíram tais experiências" (GIROUX, 1997:30)

Uma reflexão sobre as implicações metodológicas deste entendimento remete à investigação das interações entre o fazer teatral e três campos distintos de conhecimento: cultura, política e linguagem. As três perspectivas não são excludentes; é comum serem cruzadas em uma mesma abordagem, mas a identificação maior com uma delas caracteriza as opções metodológicas.

A interação Teatro - Cultura implica reflexões de ordem distintas. Em primeiro lugar, o trabalho com o texto, que amplia e acentua o caráter do fazer teatral na escola como possibilidade de levar o aluno a se colocar no lugar de outra pessoa, de outra época e lugar. Esta perspectiva é expandida quando o processo dramático tem um texto como referência, o qual além de ampliar o repertório do aluno, possibilita experiências de cunho intercultural.

Em segundo lugar, a noção do 'drama como metáfora da maneira que vivemos', que introduziu formas de cerimônias e rituais no fazer teatral. Neste aspecto é acentuada a influência de Victor Turner (1974; 1982), para quem os rituais marcam a transição entre dois estados de acomodação em uma atividade cultural, e localizam o teatro na fronteira, à margem daquilo que as formas mais tradicionais consideram como "o estabelecido".

A presença do ritual nos escritos sobre teatro, permite elaborar uma síntese de suas características: "Os rituais podem tomar várias formas, mas são geralmente descritos como manifestações coletivas, com movimentos padronizados em seqüências que são caracterizadas pelo seu alto teor teatral, usualmente incluindo gestos, canções ou sons, cores ou luzes, e vozes, tudo coordenado e orquestrado em torno de um único tema”. (CABRAL, 2001:56). O potencial do ritual teatral deriva assim de seus elementos constitutivos: se caracteriza como uma experiência, incorpora um status simbólico, refere-se a um processo ou a um grupo de ações performáticas e contém estruturas com qualidades formais e relações definidas (ver SCHECHNER, 1993:12-13; PAVIS, 1996: 1-21; e COUNSELL, 1996:143-178).

Jonothan Neelands, ao focalizar procedimentos de ensino que estimulam o desenvolvimento de ações poéticas, descreve o ritual como "delimitado por regras e códigos tradicionais, usualmente repetitivos, o que requer dos participantes a submissão à cultura e à ética de um grupo". Neelands aponta campos culturais contemporâneos, onde rituais acontecem: 
iniciação de gangues, testemunhos em juris, eleições, juramentos de escoteiros e bandeirantes, tribos indígenas. As oportunidades de aprendizagem decorrentes de sua utilização em processos de ensino, segundo o autor, incluem o levantamento da ideologia ou ética do grupo, que aparece simbolizada na atividade ritualística; a característica altamente estruturada desta atividade, a qual requer atitude reflexiva; uma estrutura simples de ser planejada e acompanhada. (NEELANDS, 1990: 40).

A interação Teatro - Política prioriza a delimitação do contexto social e das circunstâncias sócio-políticas a serem focalizadas. Entre as perspectivas teóricas que influenciaram o pensamento pedagógico nesta direção estão as de Kenneth Burke (1945, 1950) e Erving Goffman (1974). A preocupação central de Burke é o estabelecimento de conceitos e estratégias para a análise das motivações e recursos usados pelas pessoas (consciente ou inconscientemente) para tentar influenciar as opiniões e ações uns dos outros. Qualquer abordagem sobre as motivações políticas, segundo Burke, deve responder a cinco questões que são centrais ao drama: o que foi feito (ato), quando ou onde foi feito (cena), quem fez (agente), como fez (agência), e porquê (propósito). Goffman detalha e aprofunda a noção de enquadramento e distanciamento (Frame Analysis), central ao fazer teatral. As teorias de Burke e Goffman foram incorporadas no campo da pedagogia por Dorothy Heathcote. No primeiro caso, com a introdução da investigação cênica dos "Cinco Níveis de Significação" (Five Layers of Meaning): Ação, Intenção, Motivação, Modelo, Visão de Mundo; pela perspectiva de Goffman, com o desenvolvimento das "Perspectivas de Distanciamento" (Frames Distancing), onde a autora especifica nove funções através das quais o professor e/ou alunos interagem com a situação: participante, guia, agente, autoridade, relator, repórter, pesquisador, crítico, artista (Byron, 1990).

As abordagens que investigam a relação entre Teatro e Linguagem enfatizam que o teatro, assim como as demais formas de arte, se distingue das experiências cotidianas pela associação consciente entre forma e conteúdo a fim de engajar o intelecto e as emoções no processo de significação artística. A suposição é que o entendimento das possibilidades e limitações da forma oferece insights sobre o fazer teatral e permite o controle sobre o meio de expressão e seu uso pessoal e social. As influências no ensino de teatro, segundo esta perspectiva, remetem a Wittgenstein (1961) e podem ser sintetizadas em seu famoso dictum 'os limites da minha linguagem são os limites do meu mundo'. O pensamento de Wittgenstein é o pano de fundo da obra de David Best (1985; 1992), cuja filosofia da educação e da arte está voltada a erradicar as dicotomias associadas à relação entre sentimento e razão na criação e fruição artística. No campo da metodologia é possível observar como as distintas 
abordagens investigam, convenções e regras (através de jogos e estratégias) associadas à estruturação da atividade dramática, como indicadoras das maneiras pelas quais tempo, espaço e presença interagem e são formatados para criar significados em cena.

\section{Considerações finais}

As interações do teatro com distintas áreas de conhecimento tiveram ressonância na pedagogia e influenciaram a reflexão metodológica. As três influências brevemente assinaladas acima permitiram repensar o ensino do teatro nas últimas duas décadas. Se a livre expressão representou uma reação a uma tradição de textos memorizados e 'marcados' pelo professor, hoje diferentes níveis de mediação podem ser observados: o jogo dramático, o jogo teatral e o drama buscam formas de investigar as funções e o papel do professor para conduzir os alunos no processo de criação cênica a partir de novos parâmetros.

Subjacente a estas mediações está o entendimento de que se o teatro tem o potencial de promover mudanças, estas decorrem da inseparabilidade das dimensões cultural (contexto social e artístico do grupo), pessoal (o desenvolvimento de habilidades - aquisição de linguagem e convenções artísticas) e política (o objetivo da atuação do grupo). A complexidade do equilíbrio entre estas dimensões requer um debate contínuo em torno de realizações cênicas. Este debate deve incluir os atores destas realizações - os alunos. Para que estes possam acompanhar os debates e se beneficiar com eles, é necessário familiarização com os discursos poético, cultural e político.

Assim, a importância de refletir sobre as formas de mediação na construção dos tex tos dramático e teatral no espaço da sala de aula, está no fato de que é neste contex to que ele será acessível a todas as crianças, democraticamente. O 'jogar’ com o texto (seja este clássico ou contemporâneo) pode aqui significar a ampliação da percepção estética e a aquisição de conhecimentos artísticos.

\section{Referências Bibliográficas}

BEST, David. The Rationality of Feeling. Londres: The Falmer Press, 1992. BOURDIEU, P. O Poder Simbólico. Rio de Janeiro: Bertrand Brasil, 2001. . A Distinção - crítica social do julgamento. São Paulo: Editora Zouk e EDUSP, 2007.

BYRON, K. The Fight for Drama - The Fight for Education. Newcastle upon Tyne: Occasional Publication by NATD, 1990. 
CABRAL, B. "O Professor Dramaturg e o Drama na Pós-Modernidade", in OuvirOUver (Ed. Narciso Telles). Uberlândia: EDUFU, 2007, pp 47-56.

"O Professor-Diretor e a busca da teatralidade em contextos periféricos", in O Teatro Transcende, Blumenau: FURB, 2004, pp 08-15.

CARLSON, M. Performance - a critical introduction. Londres: Routledge, 1996.

CHACRA, S. Natureza e Sentido da Improvisação Teatral. São Paulo: Perspectiva, 1983.

COUNSEll, C. e WOLF, L. Performance Analysis - an introductory coursebook. Londres: Routledge, 2001.

DESGRANGES, F. Pedagogia do Teatro: provocação e dialogismo. São Paulo: Hucitec, 2006.

GIROUX, H. Cruzando Fronteiras do Discurso Educacional. Porto Alegre: Artmed, 1999.

Os professores como intelectuais - rumo a uma pedagogia crítica da aprendizagem. Porto Alegre: Artes Médicas, 1997.

GOFFMAN, E. Frame Analysis: An Essay on the Organization of Experience. Harmondsworth: Penguin, 1974.

GROTOWSKI, J. Towards a poor theatre. Londres: Methuen, 1980.

HEATHCOTE, D. The Fight for Drama - The Fight for Education. (ed. Ken Byron) NATD - National Association for the Teaching of Drama. Newcastle upon Tyne: 1990.

KOUDELA, I. Texto e Jogo. São Paulo: Perspectiva, 1996. Brecht na Pós-Modernidade. São Paulo: Perspectiva, 2001.

LEWICKI, T. From 'play way' to 'dramatic art'. Roma: LAS, 1996.

NEELANDS, J. Structuring Drama Work. Cambridge University Press, 1990.

O’NEILL, C. Drama Worlds - a framework for process drama. Londres: Heinemann, 1995.

PUPO, M.L.S.B. Diferentes abordagens em teatro-educação. Boletim Informativo do Instituto Nacional de Artes Cênicas. Setembro, 1986.

O lúdico e a construção do sentido. Sala Preta. São Paulo: ECAUSP, junho 2001, pp. 181-7.

SLADE, P. Child Drama. University of London Press, 1954.

SPOLIN, V. Improvisação para o Teatro. São Paulo: Perspectiva, 1979.

TURNER, V. From Ritual to Theatre: The Human Seriousness of Play. New York: Performing Arts Journal, 1982.

WAY, B. Development Through Drama. Londres: Longman, 1967.

WITTGENSTEIN, L. Tractatus Lógico-Philosophicus. Londres: Routledge, 1961. 